\title{
Épica moderna y aviación en el socialismo argentino durante el período de entreguerras
}

\author{
Modern epic and aviation in Argentine socialism during the interwar period
}

\author{
Javier Guiamet \\ javierguiamet@hotmail.com \\ Universidad Nacional de La Plata, Argentina
}

Recepción: 03 Febrero 2020

Aprobación: 15 Junio 2020

Publicación: 01 Marzo 2021

Cita sugerida: Guiamet, J. (2021). Épica moderna y aviación en el socialismo argentino durante el período de entreguerras. Sociohistórica, 47, e123. https://doi.org/10.24215/18521606e123

\begin{abstract}
Resumen: Este artículo analiza la cobertura realizada por $L a$ Vanguardia - periódico oficial del Partido Socialista Argentinode las noticias ligadas al desarrollo de la aviación durante el período de entreguerras. El socialismo argentino siguió con sumo interés estas noticias, que se constituyeron en poderosas narrativas sobre el progreso y la modernidad, y que circulaban intensamente al nivel de la cultura de masas. Creemos que en el abordaje de este objeto es posible analizar el modo en que los socialistas se apropiaron del imaginario de lo moderno, al mismo tiempo que puede iluminar un acercamiento estratégico hacia la cultura de masas.
\end{abstract}

Palabras clave: Partido Socialista, Período de entreguerras, Argentina, Épica moderna, Cultura de masas.

Abstract: This article analyzes the coverage made by $L a$ Vanguardia-the official newspaper of the Argentine Socialist Party- of the news related to the development of aviation during the interwar period. Argentine socialism followed with great interest these news stories that became powerful narratives about progress and modernity and that circulated intensely at the level of mass culture. We believe that in approaching this object it is possible to analyze the way in which the socialists appropriated the imaginary of the modern, while at the same time it can illuminate a strategic approach to mass culture.

Keywords: Argentine Socialist Party, Interwar Period, Modern Epic, Argentina, Mass Culture.

\section{INTRODUCCIÓN}

El 11 de febrero de 1926 aparecía en tapa de La Vanguardia una imagen que cubría gran parte de la mitad superior de la página. Si bien no resultaba extraño que el periódico, órgano oficial del Partido Socialista argentino (PS), recurriera a caricaturas y fotografías para acompañar sus notas, el tamaño y la centralidad otorgadas a esta imagen en particular sugerían, sin dudas, una ocasión especial. A partir del montaje de tres fotografías distintas, la imagen hacía alusión a la llegada del Plus Ultra, avión español que por primera vez había unido en vuelo a la Península Ibérica con el Río de La Plata. En la parte superior se podía distinguir al hidroavión sobre el agua del río, abajo la multitud reunida para recibirlo y en el margen izquierdo superpuesto a ambas imágenes, Ramón Franco, el comandante de la expedición, en su llegada a Buenos Aires. 
En sintonía con lo que sucedía en el país, el PS siguió con gran atención -a través de las páginas de La Vanguardia- las vicisitudes del "magistral vuelo" emprendido por Franco y su tripulación, el cual fue objeto de numerosos homenajes en su arribo a Montevideo, y luego a Buenos Aires. Tanto es así que unos días después Caras y Caretas ponía en tapa el rostro del comandante Franco con la leyenda "El héroe del espacio", lo que sintetizaba el sentimiento compartido por aquellos días.

La expectativa suscitada por el arribo del Plus Ultra a la Argentina se vinculaba a un interés más general por las experiencias de aviadores que conquistaban nuevas rutas aceptando el desafío de unir por aire los distintos continentes del mundo. La trascendencia que adquirieron estos desafíos a nivel mundial, por la que los aviadores podían recibir importantes premios económicos y adquirir una popularidad que los encumbraba como héroes, ha llevado a Guillermo Giucci a hablar de una "modernidad cinética" (2006).

Este proceso, que tuvo gran relevancia no solo por las posibilidades económicas que inauguraba sino también por el impacto cultural que implicaba la experiencia de un mundo más conectado, empalmó en Argentina con un profundo proceso de modernización técnica cuyas consecuencias se desplegaron sobre un conjunto variado de esferas de la sociedad.

El alcance de estas transformaciones no se limitó al plano de lo material, sino que permeó el imaginario popular alimentando fantasías sobre el progreso y la modernidad, que circularon intensamente al nivel de la cultura de masas. En este sentido, las narrativas sobre la aviación y sobre los pilotos que decidían empujar los límites de lo posible alimentaron el imaginario sobre una modernidad donde todo se podía conquistar. Esto sucedía al mismo tiempo que en el país empezaban a desarrollarse las primeras rutas comerciales, las cuales ayudaron a forjar, como ha señalado Melina Piglia, una "conciencia aeronáutica" (2015).

Los socialistas argentinos, que en las primeras décadas del siglo XX se presentaban como la única fuerza "moderna" de la política argentina, compartieron esta fascinación ampliamente extendida en el resto de la sociedad. La misma se sustentaba en la confianza de que el progreso de la humanidad desembocaría, de modo teleológico, en una sociedad socialista, y, también, sobre un ideal muy alto del valor de la ciencia y el supuesto de que estos exploradores -que se volvieron, en muchos casos, ídolos populares- eran personas modélicas para el resto de la sociedad.

Este trabajo se propone recuperar el modo en que se entremezclaban estas dimensiones en la recepción que hacía el socialismo de un fenómeno de gran popularidad a nivel mundial. Para ello, se hará foco en la manera en que estas narrativas tuvieron lugar en las páginas de La Vanguardia, publicación que seguía en su fisonomía las pautas de la modernización periodística de la época, ${ }^{1}$ y que, por lo tanto, también las cubrió como fenómenos de interés general.

Creemos que en el cruce de estas coordenadas es posible profundizar el conocimiento sobre la forma en que el socialismo se vinculó con diferentes fenómenos culturales de su época, como también, en términos más generales, ampliar la mirada sobre las distintas apropiaciones del imaginario de "lo moderno" en la cultura argentina.

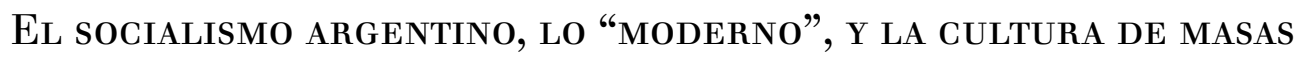

Ya desde los momentos fundacionales de la organización partidaria el PS esgrimió su carácter moderno, como principal rasgo distintivo frente al resto de las fuerzas políticas nacionales, que venían a representar "la política criolla". Como han explicado Hernán Camarero y Carlos Herrera (2005), lo que volvía "moderno" al PS era el hecho de ser un partido con programa, guiado por la ciencia, cuyo principal objetivo era actuar como escuela de cultura y civismo capaz de combatir el atraso en que se encontraba la política argentina signada por prácticas de caudillaje y clientelismo político. Desde este diagnóstico es que los socialistas se propusieron actuar como agentes de modernización de un país, que creían que no solo necesitaba de ese accionar a nivel político sino también a nivel de la cultura y de diferentes prácticas sociales. 
Estudios clásicos sobre el socialismo como los de Aricó y Portantiero han enfatizado estas características como parte del núcleo principal de la intervención socialista en la sociedad argentina. Para Aricó, al PS lo definía un proyecto democratizador e iluminista en el cual:

La democracia podía ser conquistada si la nueva clase de los trabajadores, en su enorme mayoría extranjeros, intervenía organizadamente en la vida nacional a través de una institución de nuevo tipo, de un partido político "moderno" como se proponía llegar a ser el Partido Socialista. No era ya una minoría ilustrada capaz de imponerse sobe el desorden de las masas lo que requería el país para modernizar su sistema político (1999, p. 82).

En este sentido, la tarea principal del partido era la de ejercer un rol pedagógico que sentara las bases en la sociedad para que la política se pudiera ejercer de un modo "científico" por el conjunto de la población. Del mismo modo Portantiero ha destacado que:

Toda esta vasta malla de socialización en los valores de una cultura y de patrones alternativos de comportamiento, que siempre caracterizaron a los socialistas, era una de las caras, quizás la más perdurable y transformadora, de una agrupación que intentaba postularse como agente modernizador de la sociedad frente a las pautas tradicionales que, más allá de sus diferencias, compartían conservadores y radicales (2006, p. 12).

En adelante, estas apelaciones a lo moderno, a medida que se profundizaba el proceso de modernización de la cultura, irán recorriendo nuevos caminos a través de los cuales los socialistas buscaron establecerse como pioneros frente a otras fuerzas políticas. Es por esto que el PS reivindicó para sí el temprano uso de nuevos medios de comunicación como el cine y la radio, destacando precisamente la coherencia de ese uso para el único partido "moderno" de la política argentina (Guiamet, 2017). Del mismo modo, cubrieron con énfasis, en distintas publicaciones, los avances que producía la ciencia a nivel mundial, enalteciendo a las personas detrás de esos avances como referencias ineludibles del socialismo.

Dentro de este imaginario en torno a lo moderno y a la ciencia es que la posibilidad de unir por aire diferentes partes del mundo cobró una relevancia decisiva. Los avances de la aviación fueron seguidos a nivel mundial con asombro y fascinación, dado que las posibilidades que inauguraban no solo parecían desconocer límites, sino que presagiaban importantes cambios para la convivencia de la humanidad (Osterhammel y Petersson, 2019, p. 77).

En pocos años el fenómeno creció a un ritmo vertiginoso, aun a pesar de la inmensa cantidad de accidentes trágicos que acompañaron las primeras pruebas. Si en 1903 el mundo seguía expectante el primer vuelo a motor, para el año 1927 el aviador norteamericano Charles Lindbergh era considerado el hombre más famoso del mundo (Giucci, 2006, p. 113). Estos desafíos eran animados por empresarios que vislumbraban la posibilidad de inaugurar rutas comerciales, pero también por los estados nacionales, que se interesaron en el asunto por cuestiones militares, de soberanía y de desarrollo productivo. Como destaca Giucci: "El desplazamiento aéreo es el futuro del mundo y no se puede ser moderno sin participar del impulso cinético" (2006, p. 114).

Esa asociación entre aviación y modernidad no pasó desapercibida para el socialismo argentino, que siguió con gran interés no solo los casos más resonantes, sino que dedicó espacios regulares en La Vanguardia a cubrir las novedades de diferentes vuelos que se producían en la región y también en otras partes del mundo. Este interés no se manifestó con total fuerza, sin embargo, hasta la década de 1920. Por un lado, es posible interpretar que esto podría vincularse a que, como han señalado Sarlo (1992) y Quereilhac (2016), el interés popular por la ciencia en Argentina recién en esos años pasó predominantemente a asociarse a la técnica, frente a un mayor interés previo por las ciencias del ocultismo y el espiritismo.

Sin embargo, esta idea contrasta con el hecho de que ya a principios de siglo en los bosques de Palermo se realizaban pruebas aéreas con gran concurrencia y que, en las primeras dos décadas del siglo XX, Jorge Newbery se encumbró como ídolo popular en el país (Walter, 1994). Por ello, es posible sostener que el hecho de que los socialistas recién hayan dedicado mayor atención al fenómeno en los años veinte responde, en mayor medida, a que es hacia esos años que el PS muestra una cara más flexible en torno a fenómenos ligados 
a la cultura popular (Barrancos, 1991), y, además, que vislumbra la posibilidad de hacer un uso político de diferentes expresiones de la cultura de masas (Guiamet, 2017). Por otro lado, el hecho de que los aviadores, en algunas ocasiones, fuesen considerados deportistas, también ayuda a pensar por qué es hacia los veinte que el PS muestra mayor interés, en tanto es hacia esos años que los espectáculos deportivos pasan a ocupar un lugar más importante dentro de la diagramación de La Vanguardia.

La muerte de Newbery, en este sentido, ocurrida en 1914, mereció apenas algunos recuadros menores en el periódico socialista. Inclusive, a pesar de reconocerlo a "la vanguardia del progreso de la aviación argentina" (La Vanguardia, 3/3/1914) e informar sobre los concurridos homenajes llevados a cabo en su honor, el periódico socialista se permitió, unos días después, realizar un comentario irónico sobre la virgen que le habrían regalado a Newbery antes de emprender el vuelo que terminaría en su accidente fatal. Allí, bajo el título "Milagro trágico" podía leerse:

Ignoramos qué pensarán de la virgen, después del desgraciado accidente, las dos señoritas mendocinas. No hemos de incurrir nosotros en la ridiculez de atribuirle la desaparición trágica de una vida joven o, en otros términos de afirmar que ha realizado un horroroso milagro; pero sin duda, más de un creyente sincero pensará ahora, ante la terrible desgracia, que las virtudes atribuidas a una imagen son simples supercherías de la iglesia. (La Vanguardia, 5/3/1914)

Comparado con las reseñas laudatorias que recibirán otros aviadores en años futuros por parte del PS, la posibilidad de aprovechar los incidentes de su muerte para denostar las creencias religiosas, al punto de realizar un comentario que podía considerarse ofensivo, muestra la ajenidad que el PS tenía aún con este tipo de fenómenos a pesar del carácter popular del luto dedicado al aviador. Si más adelante los aviadores serán vistos como parte del progreso de la sociedad, de una civilización que avanza hacia el socialismo, en el caso de Newbery su figura todavía parece restringida a las secciones deportivas, que, como mencionamos anteriormente, aún eran bastante pequeñas en La Vanguardia.

Mayor atención recibirán dos años después los militares Eduardo Bradley y Ángel María Zuloaga, cuando, en ocasión del centenario de la declaración de la independencia, se lanzarían a cruzar por aire la cordillera de los Andes en un globo bautizado "Jorge Newbery". Este caso, si bien el espacio en el periódico seguía siendo limitado una columna titulada "La proeza", apareció en tapa de La Vanguardia reivindicando los valores detrás de semejante empresa. En esta ocasión los personajes en cuestión sí fueron objeto de elogios que integraban sus acciones a esferas de mayor significación para el socialismo. Al respecto señalaban:

\footnotetext{
Ha repercutido hondamente la travesía de la cordillera de los Andes, efectuada anteayer por los señores Eduardo Bradley y Ángel M. Zuloaga. El espíritu popular es siempre certero, y las emociones que lo embargan tienen la encomiable virtud de la sinceridad.

Y no puede ser de otro modo. Cuando dos hombres jóvenes y dotados de una férrea voluntad, guiados por un ideal, por una esperanza que es un quimera para muchos, abandonan los cálidos afectos del hogar y de la amistad y del país nativo para afrontar los peligros de una empresa cuyo precio puede ser el de la vida, cuando ello ocurre, hay motivos más que suficientes para dispensar el laudable elogio y tributar las palmas justicieras.(La Vanguardia, 26/6/1916)
}

La gesta de Bradley y Zuloaga, calificada de hazaña por La Vanguardia y de amplia repercusión a nivel nacional, mostraba de esta manera un cambio frente a la ajenidad mostrada con respecto a Newbery, aunque aún se mostrara lejos de la atención que suscitaría este tipo de noticas a partir de la década de 1920. En este sentido, la apertura mostrada por el Partido hacia estos años, si bien no estuvo exenta de prevenciones, permitió un vínculo mucho más estrecho con los diferentes fenómenos que atravesaron la cultura argentina en el período de entreguerras.

\section{"LOS GRANDES VUELOS"}

Como señalamos al comenzar este trabajo, la llegada del Plus Ultra al Río de la Plata en 1926 mereció una cobertura extensa por parte de La Vanguardia, en sintonía con la atracción que generó el vuelo comandado por Ramón Franco en Buenos Aires y Montevideo. ${ }^{2}$ Si bien la empresa tenía un marcado rasgo 
nacionalista y también una significación histórica específica al vincular el vuelo al pasado imperial español en el Río de la Plata, en su celebración del acontecimiento el PS eligió destacar otros rasgos que se encontraban alejados de la tradición hispánica. Es así que:

El vuelo es una prueba admirable del perfeccionamiento de la técnica y de la fuerza de resistencia del hombre cuando se lanza al peligro animado de amplio ideal humano. (...) Como avanzadas de la civilización que, en el perfeccionamiento de la técnica, tiende a fundir estrechamente a todos los pueblos de la tierra, en grande y soberbio internacionalismo: saludamos a Franco y sus compañeros (La Vanguardia, 11/2/1926).

Cabe destacar que, como sugiere la cita, para el PS las avanzadas de la civilización eran fundamentalmente vistas como avanzadas de la ciencia y la técnica. Más incluso, el PS no tenía necesariamente una actitud condenatoria frente al imperialismo europeo, ya que podía ser considerado un mal necesario o menor frente a la necesidad de que la ciencia guiara el avance de la humanidad (Poy, 2014). En ocasiones como esta, el ideal por la modernidad europea superaba en importancia a otras cuestiones que de todos modos criticarían, como el nacionalismo, el militarismo o las guerras capitalistas. Ideológicamente el PS se encontraba ante la necesidad de depurar el faro de la civilización occidental de los elementos contarios a su doctrina, para continuar encumbrándolo como norte último de un desarrollo civilizatorio que arribaría al socialismo.

En esta línea, el vuelo era importante también porque inauguraba la posibilidad de un contacto más permanente con el continente europeo. Allí nuevamente el PS buscó realzar el valor de la técnica para proyectar un futuro cercano en que la ruta aérea pudiese funcionar con regularidad en el tránsito de pasajeros, lo que, sin lugar a dudas, enriquecería la cultural local.

En los días siguientes la cobertura en torno al Plus Ultra se desplazaría a discutir las diferentes apropiaciones que se realizaban de la "hermosa correría por el cielo atlántico" en el contexto local ( $\mathrm{La}$ Vanguardia, 11/2/1926). En efecto, uno de los primeros blancos de las críticas socialistas fue el diario $L a$ Nación, que en su descripción de la tripulación olvidó mencionar al mecánico Rada, único obrero del vuelo, y del cual La Vanguardia replicó una elogiosa semblanza por parte del comandante Franco. A continuación las críticas se dirigieron en primer lugar a la Iglesia -nuevamente se celebraba la ausencia de Franco del $T e$ Deum-; luego, a los "partidos criollos", que usaban la popularidad de Franco para distraer de temas más importantes, y, por último, a los militares,que resultaron el tercer blanco.

Allí, en ocasión de un agasajo realizado a la tripulación, los socialistas serían particularmente críticos con las palabras del general Uriburu, cuyas exaltaciones de la raza hispánica y del rey Alfonso XIII serían señaladas crudamente por la omisión del pueblo español, el cual era en última instancia quien había "pagado" por la travesía con el fruto de su trabajo. Vemos así que, si bien el PS participaba de la fascinación popular en torno al vuelo, no dejaba por ello de disputar los sentidos respecto al mismo, privilegiando una mirada sensible a al pueblo trabajador, pero, sobre todo, trazando el desafío dentro de una narrativa sobre el progreso que ocluía en importancia al anhelo imperial español.

A pesar del carácter resonante y singular que adquirió la llegada del Plus Ultra al Río de la Plata, y que le valió semejante centralidad en el periódico socialista, la cobertura de diferentes vuelos y raides se convirtió, a partir de la década de 1920, en algo muy frecuente en las páginas de La Vanguardia, que ocupaba, por lo general, la contratapa del periódico.

En 1924, el mayor Pedro Zanni consiguió el apoyo del Aeroclub Argentino para emprender un vuelo alrededor del mundo. El raid, que partió en junio de ese año desde Holanda, no pudo completar la vuelta dado que tuvo problemas primero en Hanói, donde tuvo que cambiar de avión, y luego en Tokio, donde un nuevo accidente malogró la experiencia. Aun así, La Vanguardia cubrió día por día las distintas vicisitudes de la travesía emprendida por el militar argentino, cuyo objetivo era el de posicionar a Argentina dentro de los países protagonistas de la "modernidad cinética". Como era de esperarse, el periódico socialista no se privó de perfilar algunos rasgos propios en la cobertura, como el de denominar a la travesía "el vuelo Zanni-Beltrame”, 
ponderando de igual manera al aviador y al mecánico que lo acompañaba, aunque por fuera de ese detalle el seguimiento haya estado en línea con el interés que generaba la travesía a nivel más general.

En ese sentido, si el vuelo de Zanni buscaba incorporar a la Argentina dentro de los países innovadores en el viaje aéreo, La Vanguardia se ocuparía de trazar esa genealogía al ubicarlo dentro de "Los vuelos mecánicos alrededor del mundo", haciendo hincapié, como se puede observar en ese enunciado, en la dimensión técnica. A su vez, acompañaron cotidianamente la narrativa sobre el vuelo informando sobre todas las vicisitudes del viaje, replicando cables internacionales junto a, en algunas ocasiones, mapas del trayecto realizado con explicaciones sobre la mecánica del avión y su diseño para que fuera comprensible al público del periódico.

Si bien el centro de la narrativa en esos días lo ocupó el vuelo del aviador argentino, pegadas a las noticas sobre su travesía aparecían anunciadas otras que se estaban realizando en simultáneo en otras partes del mundo. La desaparición y posterior aparición del aviador italiano Locatelli, el cruce del Atlántico a cargo de un grupo de aviadores norteamericanos y otras noticias del estilo acompañaron al vuelo de Zanni en la contratapa de La Vanguardia, aunque sin opacarlo, dado que:

El tema del día en los círculos deportivos lo constituye la forma admirable con que el aviador argentino Pedro Zanni realiza su vuelo alrededor del mundo, reconociéndose que en la distancia recorrida y el tiempo empleado para llegar a Kanschi ha batido un verdadero record de habilidad y pericia.

Al comentar la hazaña se elogia al mecánico Beltrame, joven éste a quien se le reconocen méritos en la tarea encomendada (La Vanguardia, 4/8/1924).

La aparición conjunta de noticias sobre vuelos y raides en la contratapa del periódico dio lugar prontamente a una sección de aparición muy frecuente, titulada "Los grandes vuelos". De esta manera, $L a$ Vanguardia dio lugar durante aquellos años a la cobertura de un fenómeno que ya se había constituido en una narrativa muy popular dentro las ofertas de entretenimiento. Uno de los personajes encumbrado por esa popularidad, que se replicaba a distintos niveles de la cultura de masas, fue el aviador norteamericano Charles Lindbergh, quien en 1927 se convirtió en el primer hombre en cruzar el océano atlántico solo y sin escalas en un vuelo que unió a Nueva York con París en poco más de 34 horas. La travesía, de enorme repercusión a nivel internacional, fue igualmente celebrada por el socialismo, que la aclamó como "La gran hazaña del día". Pese a que el título resultaba por demás laudatorio, cabe destacar que la enunciación deslizaba un sentimiento de habitualidad en el que las hazañas, aunque se superasen unas a otras, resultaban un panorama cotidiano para el espectador. Este clima donde los desafíos y las epopeyas constituían un escenario frecuente era denotado por el socialismo en su forma de abordar la notica y en el modo de señalar el entrelazamiento que el evento tenía con el mundo del espectáculo. Es así que:

Apenas conocidas las noticas de la aproximación del aviador Lindbegrh a las costas de Francia, millares de personas se trasladaron al aeródromo de Le Bourget, de forma que, cuando el aviador aterrizó fue rodeado por una inmensa muchedumbre que lo aclamaba con gran entusiasmo. La noticia de la llegada del aviador Lindbergh se difundió con rapidez asombrosa por toda la capital mediante los transparentes luminosos y por las ediciones especiales de los diarios que anunciaban el éxito completo obtenido por el aviador norteamericano.

En los teatros y cinematógrafos la noticia fue dada por medio de proyecciones luminosas, suscitando gran entusiasmo entre los espectadores, quienes, en medio de grandes aplausos, pidieron que las orquestas ejecutaran el himno norteamericano, que fue oído de pie por los espectadores y estruendosamente aplaudido (La Vanguardia, 22/5/1927).

Sumado a este entrelazamiento, que el evento presentaba con el mundo del espectáculo, La Vanguardia no se privaría de destacar las cualidades personales del aviador elogiando que no hiciera alarde de ninguna virtud racial para explicar su proeza, y destacando, a su vez, los aportes que había hecho al progreso de la técnica. Es así que para el periódico socialista:

Esta hazaña quedará grabada en la historia y el progreso de la humanidad como un jalón glorioso del valor y la ciencia, pues Lindbergh agregó detalles propios que perfeccionaron el aeroplano que llevaba; sustituyó y agregó lo que pareciole más útil, inclusive le aplicó un periscopio de su propia inspiración que le permitió observar más fácilmente el trayecto (La Vanguardia, 23/5/1927). 
Estas cualidades del aviador y de la empresa que había acometido tenían la capacidad inclusive de opacar el hecho de que Lindbergh fuese considerado un héroe nacional de los Estados Unidos, país que, en el momento, era blanco de críticas muy duras de parte del socialismo por el proceso desatado en contra de los anarquistas Sacco y Vanzetti, quienes serían ejecutados unos meses después. El mismo día que se elogiaron las innovaciones de Lindbergh en el aeroplano, La Vanguardia informaba sobre el boicot que llevaba adelante el comité Pro Sacco y Vanzetti de Pergamino contra las películas de la Metro Goldwin Mayer, y prevenía a la población de los peligros del "imperialismo yanqui" alentando a "[pegarles] en la cartera, que ellos allí tienen el corazón" (La Vanguardia, 23/5/1927).

De esta manera, y más allá de las prevenciones que podían suscitar algunas de las aristas del fenómeno, el entusiasmo que suscitaban estas epopeyas permitió que "Los grandes vuelos" se convirtiera en una sección habitual de la contratapa del periódico socialista. Se apelaba allí al interés que generaban estos héroes modernos no solo entre la población, sino también en las filas del socialismo. Los constantes accidentes, desapariciones, y, en algunos casos, apariciones mantuvieron en vilo al periódico, lo que ayudó a otorgarle espectacularidad a la cobertura.

Un ejemplo paradigmático de esto podemos encontrarlo en la experiencia de los aviadores uruguayos comandados por el mayor Larré Borges, quienes en 1927 se propusieron ser los primeros latinoamericanos en cruzar el océano Atlántico. La travesía que estaba planeada para iniciarse el 3 de marzo con el tramo entre Casablanca y Las Palmas sumió al público en el desconcierto, dado que el avión partió pero nunca llegó a destino. Los días siguientes La Vanguardia se sumó a la inquietud por la suerte de los aviadores uruguayos replicando las noticias que llegaban desde Europa, a la vez que compartía las distintas hipótesis sobre lo ocurrido. El 4 de marzo el periódico socialista anunciaba que se desconocía el paradero de los aviadores a la vez que daba cuenta de la inquietud que esta situación generaba en Montevideo: "se tiene plena fe en el piloto, con todo, el público está viviendo horas de intensa emoción. Numerosos grupos de personas permanecen frente a las pizarras anunciadoras de los diarios, ansiosos de conocer noticias que expliquen el retardo" ( $L a$ Vanguardia, 4/3/1927).

Los dos días siguientes el periódico volvió a informar sobre el desconocimiento del paradero y la suerte del avión, hasta que el 7 de marzo pudo comunicar, con énfasis, que los aviadores se encontraban con vida y que habían sufrido un accidente cerca de la costa de Marruecos en la región del Río de Oro. Recién al día siguiente se conocerían las condiciones en las que se encontraban los pilotos uruguayos, quienes luego de aterrizar forzosamente en el mar habían logrado llegar nadando a la costa donde fueron apresados por una tribu de moros, que, además, habría despedazado parte por parte el avión en busca de algún botín de valor.

A partir de aquí la expectativa quedó depositada en las negociaciones que se iniciaron para conseguir la liberación de la tripulación comandada por Larré Borges. Las peripecias del hecho lograron darle mayor dramatismo al incidente, dado que los aviadores fueron alejados de la costa y conducidos por una "caravana indígena" hacia Cabo Juby, a la que saldría a dar encuentro un destacamento de soldados españoles. Si bien el grueso de las noticias eran auspiciosas con respecto a la posibilidad de obtener la liberación de los uruguayos, el PS expresaría su preocupación por el hecho de que llegaban de Madrid noticias contradictorias, ya que algunos diarios habían comenzado a señalar que la tribu no era pacífica como se creía, sino belicosa, y que podía esperarse un combate para liberar a los prisioneros.

Recién el 12 de Marzo, más de una semana después de ocurrido el accidente, pudo La Vanguardia informar con mayor seguridad sobre lo ocurrido con la tripulación uruguaya. En esta ocasión, aparte de explicar las causas del accidente y comentar la iniciativa originada en España de realizar una colecta a favor de que los uruguayos pudiesen comprar un nuevo avión para completar el raid, el periódico socialista dedicó un pasaje a describir la vida de los aviadores entre los indígenas. Allí destacaron que:

Pertenecían los naturales a la Cabila de Ait Lassen, y no demostraron mayor animosidad contra los huéspedes. Al contrario, para eludir que cayeran en poder de los merodeadores del desierto, los condujeron con infinidad de precauciones a la sede 
de su tribu, donde se les colmó de promesas, cosa que no impidió por cierto que se les substrajera el equipaje y otros objetos de valor.

En circunstancias en que se les internaba, los aviadores recibieron alimento y toda clase de atenciones. Por otra parte, ignoraban completamente que se exigiría rescate. El ánimo de los moros parecía bien dispuesto hacia los extranjeros, pues expusieron a los mismos su admiración por España y sus simpatías por el Uruguay (La Vanguardia, 12/3/1927).

De esta manera, a través de una narrativa que semejaba a la del “indio amigo", el periódico socialista se permitía sumar una cuota de exotismo a un relato que ya estaba lleno de elementos atractivos para el público lector.

Aunque finalmente el raid tuvo que interrumpirse, Larré Borges lograría convertirse en el primer latinoamericano en cruzar el Atlántico, cuando, dos años después, no sin una cuota importante de peripecias y zozobra, lograra unir en vuelo España con Brasil.

En esta ocasión, si bien la travesía fue exitosa, un accidente llegando a Brasil volvió a suscitar la atención y la inquietud del público que seguía expectante la suerte de su empresa. Es así que el 17 de diciembre de 1929, un día después de que una multitud saludara el despegue del avión en Sevilla, La Vanguardia titularía “¿Cruzaron el Atlántico Larré Borges y Challe?”. La pregunta se debía a que el avión no había aparecido en el aeropuerto de Natal donde se lo esperaba. La nota, sin embargo, especulaba con la posibilidad de que el cruce se hubiese realizado, ya que diferentes barcos y postas marítimas habían avistado al avión en vuelo en correcta ejecución de la ruta trazada. No sería hasta el día siguiente que llegaría la información acerca del aterrizaje forzoso que el avión había tenido que realizar en un bosque cerca de Maracuja, estado de Río Grande do Norte. El accidente, que aparentemente se había producido por una faltante de gasolina, había terminado con el avión dado vuelta entre los árboles y ambos pilotos inconscientes. Allí, La Vanguardia recogía el relato de Larré Borges, quien aseguró que al despertar y notar que su compañero se encontraba herido había decidido salir caminando en búsqueda de ayuda, sabiendo también, que los estarían esperando en Natal.

Nuevamente el carácter espectacular del acontecimiento era denotado por el periódico socialista, que relataba el impacto del hecho en Montevideo:

En las últimas horas de la tarde de ayer, numerosos grupos de personas se apiñaban frente a las redacciones de los diarios, en procura de noticias. Anoche, a pesar del viento y de la lluvia aumentó la ansiedad, aglomerándose el público hasta las primeras horas de la madrugada. El silencio desesperante de los periódicos comenzó a producir la angustia del caso, aunque los más animosos confiaban en que aparecieran.

Así transcurrió la noche, comentándose la ausencia de informes telegráficos en la vía pública, en la salida de los teatros y cinematógrafos, en los cafés y en los hogares. Por último, cuando esta mañana los diarios dieron la noticia de la caída del aeroplano en tierras brasileñas, con el resultado que se conoce respecto a los pilotos, una honda impresión de pesar embargó todos los corazones (La Vanguardia, 18/12/1929).

Podemos ver, así, que en la misma medida que La Vanguardia participaba de la construcción de un relato espectacular del incidente, también daba cuenta en su descripción de la ligazón que el fenómeno tenía, de modo más general, con las formas del entretenimiento destinadas a grandes públicos. A su vez, frente a distintas valoraciones del desafío emprendido por Larré Borges, el periódico socialista no se privaría de ponderar su propia visión al caracterizar de "heroico" al piloto uruguayo.

Hacia la década de 1930 ganaron visibilidad entre estos relatos las proezas aéreas realizadas por mujeres. Aquí también el periódico socialista replicó los principales tópicos que buscaba realzar dentro del fenómeno, como podían ser la audacia de las aviadoras, el valor de la técnica al servicio de las pruebas, y, por supuesto, la reivindicación del elemento obrero que hacía posibles estos vuelos.

Todos estos temas se hicieron presentes en la cobertura del fallido raid emprendido por la actriz suiza Myriam Stefford, quien en 1931 se propuso unir catorce provincias argentinas en solo 4 días. La empresa de la "audaz y entusiasta aviadora" fue seguida con interés por La Vanguardia, que la apodó "La Stefford” (23/5/1927), y se ocupó de realzar el entusiasmo popular que suscitaba en su arribo a las distintas provincias. Si bien el vuelo no suponía una gran innovación técnica, el periódico dio cuenta también de las particularidades de la aeronave en la que emprendió el raid. 
El hecho de que se tratara de una mujer que piloteaba el avión -frente a la abrumadora mayoría de hombres en las primeras pruebas aéreas- no modificó sustancialmente el tratamiento otorgado por La Vanguardia al relato de los distintos sucesos que fueron parte de la travesía. Es así que el deseo de continuar frente a un primer accidente, que obligó a cambiar de avión, fue aplaudido, en tanto demostraba los "bríos" ( $L a$ Vanguardia, 22/8/1931) de la aviadora, mientras que las noticias también se ocuparon de dar un lugar relevante al mecánico que la acompañaba.

Cuando producto de un segundo accidente la aviadora perdió la vida, La Vanguardia se ocupó de recapitular la biografía de la actriz suiza destacando su espíritu aventurero, y, también, se dedicó a reconstruir los principales hitos de la malograda travesía que se había cobrado su vida y la del mecánico Fuchs. Al día siguiente, La Vanguardia destacó la concurrencia que se había reunido en la estación Retiro para homenajearlos y, llamativamente, omitió, al mencionar que el esposo de la actriz había organizado el sepelio, el hecho de que se trataba de Barón Biza, el controvertido político radical que provenía de una familia terrateniente. El tratamiento sobrio del acontecimiento, centrado en la figura de la aviadora -lejano al sensacionalismo con que fue cubierta la noticia por otros medios-, reafirma el interés que el socialismo tenía por encumbrar estas experiencias dentro de una narrativa de progreso y altos ideales llevados adelante por figuras que podían considerarse modélicas para el resto de la sociedad.

Hacia el año 1937, a pesar de que las noticias sobre aviación se habían volcado mayoritariamente a seguir los acontecimientos bélicos de la Guerra Civil Española, la aviadora Amelia Earhart también se hizo un lugar dentro de las semblanzas socialistas. Es así que, en ocasión de su primer intento por dar la vuelta al mundo, cuya intención era la de convertirse en la primera mujer en realizar tal proeza, La Vanguardia destacó que el avión se encontraba "equipado como un verdadero laboratorio aéreo" (La Vanguardia, 19/3/1937), haciendo eje, una vez más, en el costado técnico de la empresa.

Si consideramos estos casos, podemos ver de qué manera "los grandes vuelos" se convirtieron en una narrativa en la que dimensiones como heroísmo, modernidad, progreso, nacionalismo, pero también espectáculo, podían combinarse con fluidez. Aunque el socialismo no compartía absolutamente todos los elementos que se ponían en juego en estos relatos, les otorgó un lugar destacado dentro de las noticias de interés general que el periódico partidario se proponía cubrir. Además de involucrar algunos aspectos estratégicos ligados a sus intentos por ampliar el conjunto de la población al que se dirigían y de compartir la fascinación que estas epopeyas generaban, en última instancia, el PS vislumbró estas pruebas del avance de la técnica como parte insoslayable del progreso evolutivo, dentro del cual Juan B. Justo había proyectado la llegada del socialismo.

Si bien la mayor atención se la llevaban los relatos de raides - muchas veces La Vanguardia informaba en el mismo día sobre tres o cuatro vuelos de prueba diferentes que se estaban llevando a cabo alrededor del mundo-, el interés por la aviación también mereció una cobertura más general, que diera cuenta de los avances de la tecnología, y que, a su vez, realizara balances sobre el progreso efectuado en nuevas rutas que propiciarían futuros intercambios de manera regular. En este sentido, el mismo día que la contratapa del periódico informaba que se desconocía el paradero de los aviadores uruguayos, en la tapa una columna hacía un balance sobre la historia y el progreso del cruce aéreo del Atlántico (La Vanguardia, 4/3/1927). Luego de repasar los diferentes cruces, de los cuales el primero había sucedido ocho años antes en 1919, la nota daba cuenta de los distintos proyectos por cruzar el Atlántico a través de un vuelo de seis mil kilómetros sin escalas, lo que coincidía precisamente con la distancia que separaba a Nueva York de París. La posibilidad de unir dos ciudades de tanta importancia se había constituido en la nueva ambición de los aviadores, como también de empresarios que deseaban explotarla como ruta comercial. En ese sentido, La Vanguardia procuraba reproducir un balance preciso de las dificultades técnicas que aún no se habían superado para aspirar a realizar la prueba con éxito.

Del mismo modo, las novedades de la aviación comercial estadounidense merecían un recuadro en tapa del periódico, dado que "La aviación comercial, que progresa visiblemente entre nosotros, ha alcanzado en 
los Estados Unidos un desarrollo verdaderamente portentoso, casi fantástico" ${ }^{3}$ Interesada especialmente en el éxito de los vuelos nocturnos, la nota explicaba el riguroso proceso de balizamientos que había unido la costa este con la costa oeste en la ruta transcontinental más larga del mundo.

Como estas, numerosas notas aparecieron en La Vanguardia que daban cuenta del avance tecnológico que podía llevar algún día, inclusive, a que los aeroplanos tuviesen "capacidad para mil pasajeros" (La Vanguardia, 26/12/1929). El interés por el avance técnico de la aviación se expresó también en páginas enteras a modo de sección especial con un encabezado doble que unía a dos páginas, una dedicada al automovilismo y la otra a la aviación, en las que se desmenuzaban diferentes detalles de las transformaciones que se estaban produciendo a nivel de la mecánica. .

De esta manera, se replicaba en La Vanguardia, y con la misma fuerza, el poderoso interés que ejercía sobre el público general el avance de la técnica y las aventuras aéreas. Modernidad, ciencia y técnica, aparecían como faros imprescindibles del desarrollo de la sociedad futura a la que aspiraba el PS, partido que nunca dejó de detentar el título de "Defensor del Socialismo Científico" con el que encabezó al periódico partidario en sus años iniciales.

\section{Conclusiones}

Si la sociedad futura a la que aspiraban los socialismos de la Segunda Internacional resultaría el fruto de la evolución de leyes científicas, apoyar el avance del conocimiento y la técnica entre el conjunto de la población se volvió una tarea indispensable para acercarse a los objetivos de máxima que compartía el movimiento a nivel internacional. Este sesgo, aún más marcado en el socialismo argentino -dado que su tarea se llevaba a cabo en un país "atrasado" en el cual el PS era la única fuerza política que podía considerarse moderna-, llevó al partido a otorgar un valor central a cualquier manifestación que pudiera vincularse con alguna de estas dimensiones.

En efecto, si ser modernos implicaba, en principio, que se formaran partidos que no respondieran a caudillos sino a programas de ideas y que la política se elaborara a través del análisis sesudo de los problemas del país, en adelante, los socialistas argentinos irán apropiándose de los diferentes fenómenos que surgieren con el aura de lo moderno, y reivindicarían para sí mayor coherencia y pertenencia con los mismos que otros sectores que no contribuían al avance del país.

Los casos más resonantes de estas diversas apropiaciones de lo moderno vinieron de la mano del cine y de la radio. En ambos casos el socialismo argentino se adelantó al uso de estos medios para difundir la doctrina partidaria y explícitamente vinculó estas prácticas a la modernización política y cultural de la que se proclamaban protagonistas.

En el caso de la aviación, si bien el PS no podía reivindicar un uso propio en sentido estricto, sí participó de la celebración de estos acontecimientos y los integró a una narrativa sobre la modernidad y la civilización sin la cual una sociedad socialista era impensable. Frente a la variedad de sentidos en disputa, los socialistas privilegiaron el valor de la técnica, la importancia de los obreros involucrados y los nobles sentimientos de quienes empujaban al progreso de la humanidad. Sería un error subestimar el carácter genuino del interés que los socialistas mostraban por este fenómeno. Por un lado, lo evidencia el importante espacio otorgado a cubrir sus diversas aristas, pero también porque el modo en que se apropiaban de los sucesos que aparecían con el aura de "lo moderno" revela la enorme expectativa con que seguían estos acontecimientos, que parecían acercar a grandes pasos el futuro y confirmaban las nociones más evolutivas con que los socialistas vislumbraban el devenir de la historia (Martínez Mazzola, 2011).

Sin embargo, el fenómeno de la aviación en estos años, dado su carácter épico y aventurero, se constituyó también en una poderosa narrativa destinada al entretenimiento masivo. Las peripecias y zozobras de pilotos y aparatos que desafiaban la gravedad suscitaron la fascinación popular con particular intensidad. En este sentido, el interés socialista por estas historias nos obliga no solo a leerlo en relación a su idealización de lo 
moderno, sino en la apertura frente a diferentes manifestaciones de la cultura de masas, que se manifiesta más visiblemente a partir de la década de 1920.

De esta manera, la columna "Los grandes vuelos" y las secciones especiales dedicadas a la mecánica de la aviación pueden ser consideradas no solo como el elogio y celebración de la técnica moderna, sino también como un espacio dedicado a cautivar la atención de los lectores, que compitieracon otros productos de la prensa comercial.

Podemos concluir señalando, entonces, que el interés por estos fenómenos enraizó en diferentes dimensiones de particular importancia dentro del imaginario socialista, pero también que ese interés nos muestra los cambios del PS, en la medida que se mostró más permeable a las transformaciones que operaban en la cultura argentina. Si la ciencia, la cultura de masas y la épica moderna podían encontrar cauce en las aventuras aéreas, La Vanguardia se ocupó de asimilar, pero también replicar, estos relatos destinados a los grandes públicos como parte de una apertura, cuyo objetivo era acrecentar la influencia del mensaje socialista en la sociedad argentina a través de un elemento que parecía confirmar los postulados partidarios sobre el futuro.

\section{ReFERENCIAS}

Aricó, J. (1999). La hipótesis de Justo. Escritos sobre el socialismo en América Latina. Buenos Aires: Sudamericana.

Barrancos, D. (1991). Educación, cultura y trabajadores (1890-1930). Buenos Aires: CEAL.

Buonuome, J. (2016). Periodismo militante en la era de la información. La Vanguardia, elsocialismo y los orígenes de la cultura de masas en la Argentina (1894-1930). Tesis de Doctorado en Historia, Universidad de San Andrés.

Camarero, H, y Herrera, C (ed.), (2005). El Partido Socialista en Argentina: “Introducción”. Buenos Aires: Prometeo libros.

Giucci, G.(2006). “Internacionalismo y nacionalismo: el aeroplano”. Mester, Vol XXXV, pp. 111-127.

Guiamet, J. (2017). Tentaciones y prevenciones frente a la cultura de masas: Los socialistas argentinos en el periodo de entreguerras. Tesis de posgrado (Doctorado en Historia). Universidad Nacional de La Plata. Facultad de Humanidades y Ciencias de la Educación.

Martínez Mazzola, R. (2011). “Justo, Korn, Ghioldi. El Partido Socialista y la tradición liberal”, Papeles de Trabajo, 5 (8), pp. 35-52.

Osterhammel, J, Petersson, N. (2019). Breve historia de la globalización. Del 1500 a nuestros dias. Buenos Aires: Siglo veintiuno editores.

Piglia, M. (2015). En torno al viaje en avión en Argentina: representaciones y experiencias 1929-1958. Avances del Cesor, 12 (13), pp. 133-158.

Portantiero, J. (2006). Un fundador de la Argentina moderna. En C. Noble y J. B. Justo. El Patriarca Socialista. Buenos Aires: Capital Intelectual. Colección fundadores de la izquierda Argentina.

Poy, L. (2014), Juan B. Justo y el socialismo argentino ante la Primera Guerra Mundial (1909-1915). Política y Cultura, 42, pp. 155-181.

Quereilhac, S. (2016). Cuando la ciencia despertaba fantasías. Prensa, literatura y ocultismo en la Argentina de entresiglos. Buenos Aires: Siglo veintiuno editores.

Sarlo, B. (1992). La imaginación técnica. Sueños modernos de la cultura argentina. Buenos Aires: Ediciones Nueva Visión.

Walter, R. J. (1994). Politics and urban growth in Buenos Aires: 1910-1942. Cambridge: University Press.

\section{Notas}

1 Acerca del proceso de modernización de La Vanguardia, ver Buonuome, 2016. 
$2 \mathrm{Al}$ respecto, Guillermo Giucci cuenta que en 1926 se publicó La emoción de Montevideo ante el raid del Comandante Franco un conjunto de testimonios de la intelectualidad uruguaya, recogidos por Mercedes Pinto. A su vez, en Uruguay los aviadores fueron objeto de un acto de homenaje que incluyó al presidente de la república (2006, p. 119).

3 Resulta curioso que este elogio a la aviación comercial estadounidense se producía apenas unas semanas después del famoso rrack de la bolsa de Wall Street, del que sin embargo, hasta el momento, los socialistas habían dado un tratamiento lateral, posiblemente aún sin dimensionar el impacto de la crisis. La Vanguardia, 15/12/1929. 